Nys, S., Tjhie, J.H.T., Bartelds, A.I.M., Heijnen, M.L.A., Peeters, M.F., Stobberingh, E.E. Erythromycin resistance in the commensal throat flora of patients visiting the general practitioner: a reservoir for resistance genes for potential pathogenic bacteria. International Journal of Antimicrobial Agents: 26, 2005, nr. 2, p. 133-137

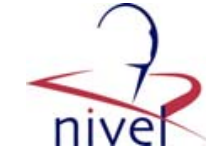

\begin{tabular}{l|l|} 
Postprint Version & 1.0 \\
\hline Journal website & $\underline{\text { http://www.sciencedirect.com/science/journal/09248579 }}$ \\
\hline Pubmed link & $\begin{array}{l}\text { http://www.ncbi.nlm.nih.gov/entrez/query.fcgi?cmd=Retrieve\&db=pubmed\&dop } \\
\text { t=Abstract\&list uids=15963697\&query hl=85\&itool=pubmed_docsum }\end{array}$ \\
\hline DOI & \begin{tabular}{l} 
10.1016/j.ijantimicag.2005.04.010 \\
\hline
\end{tabular}
\end{tabular}

\title{
Erythromycin resistance in the commensal throat flora of patients visiting the general practitioner: a reservoir for resistance genes for potential pathogenic bacteria
}

\author{
S. Nys ${ }^{A}$, J.H.T. TJHIE ${ }^{\text {B }}$, A.I.M. BARTELDS ${ }^{\mathrm{C}}$, M.L.A. HEIJNEN ${ }^{\mathrm{D}}$, M.F. PEETERS ${ }^{\mathrm{E}}$, E.E. STOBBeringh, ${ }^{\mathrm{A}}{ }^{*}$ \\ a Department of Medical Microbiology, University Hospital Maastricht, P.O. Box 5800, 6202 AZ \\ Maastricht, The Netherlands \\ b Department of Medical Microbiology, PAMM Laboratories, Veldhoven, The Netherlands \\ c The Netherlands Institute for Health Services Research (NIVEL), Utrecht, The Netherlands \\ d National Institute for Public Health and the Environment, Department of Infectious Diseases \\ Epidemiology (RIVM), Bilthoven, The Netherlands \\ e Regional Laboratory for Public Health, Tilburg, The Netherlands \\ * Corresponding author. Tel.: +31 43 3876644; fax: +31 43 3876643. E-mail address: \\ EST@Imib.azm.nl (E.E. Stobberingh).
}

\begin{abstract}
The prevalence and mechanism of erythromycin resistance in commensal throat streptococci was determined from October 2000 until December 2002 as part of an ongoing study of the NIVEL in general practice patients $(N=678)$. Resistance prevalence for $1 \mathrm{mg} / \mathrm{L}$ and $16 \mathrm{mg} / \mathrm{L}$ erythromycin was $57 \%$ and $20 \%$, respectively. The percentage of total commensal flora resistant within each patient ranged from $1 \%$ to $100 \%$ (median, $1 \%$ ). mefA was predominantly found among isolates on the $1 \mathrm{mg} / \mathrm{L}$ plates, and ermB was found in $64 \%$ of the isolates on the $16 \mathrm{mg} / \mathrm{L}$ plates. Erythromycin resistance was transferred from a commensal isolate to Streptococcus pneumoniae with a frequency of $1 \times 10^{-9}$. Commensal streptococci of general practice patients in The Netherlands form a large reservoir of transferable erythromycin resistance (genes) for potential pathogenic micro-organisms.
\end{abstract}

\section{INTRODUCTION}

Respiratory tract infections in most cases have a viral aetiology for which antimicrobial therapy is not beneficial. However, up to $60 \%$ of patients with a common cold in general practice receive antimicrobial treatment [1]. Consequently, the commensal bacterial flora of the upper respiratory tract is often exposed to antibiotics [2], and each time an antibiotic is administered irrespective of the indication the resistant micro-organisms in the commensal flora might be selected [3]. These resistant commensal streptococci play a significant role as a reservoir of antimicrobial resistance genes and might transfer different resistance traits to potential pathogenic micro-organisms such as Streptococcus pneumoniae and Streptococcus pyogenes [4]. To date, only two studies in The Netherlands have addressed the problem of resistance in commensal throat flora $[5,6]$. These studies were directed at the problem of resistance in the commensal throat flora following clarithromycin and/or azithromycin therapy in placebo-controlled double-blind studies in specific populations.

For years, macrolides have been an effective alternative for the treatment of infections due to Grampositive micro-organisms, especially in cases of allergy to $\beta$-lactam antibiotics. However, the increase 
Nys, S., Tjhie, J.H.T., Bartelds, A.I.M., Heijnen, M.L.A., Peeters, M.F., Stobberingh, E.E. Erythromycin resistance in the commensal throat flora of patients visiting the general

practitioner: a reservoir for resistance genes for potential pathogenic bacteria.

International Journal of Antimicrobial Agents: 26, 2005, nr. 2, p. 133-137

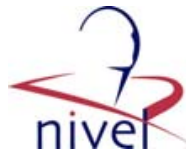

in macrolide resistance has limited the use of these antimicrobial agents [7]. Resistance to macrolides in streptococci is mainly due to two resistance mechanisms: modification of the ribosomal target of the antibiotic owing to methylation or mutation; and efflux of macrolides. Methylation is encoded by the ermBgene $\left(\mathrm{MLS}_{\mathrm{B}}\right.$ phenotype) and efflux is mediated by the mefA gene (M phenotype) $[8,9]$. Strains with an $\mathrm{MLS}_{\mathrm{B}}$ phenotype usually show high-level resistance to macrolides, lincosamides and streptogramin B, whereas strains with an M phenotype express low-level resistance to 14- and 15membered macrolides only but no cross-resistance to other antimicrobial agents $[10,11]$. So far, ribosomal methylation remains the most widespread mechanism of resistance to macrolides and lincosamides [7].

The purpose of this study was to determine the prevalence of erythromycin resistance (genes) in the commensal streptococcal flora of patients with and without an acute respiratory tract infection attending their general practitioner (GP) who participated in a GP network of The Netherlands Institute for Health Services Research (NIVEL) in The Netherlands. Furthermore, the mechanisms of erythromycin resistance, i.e. the presence of mefA and/or ermB genes, was determined as well as the possibility to transfer erythromycin resistance (genes) from a commensal streptococcal isolate to $S$. pneumoniae.

\section{MATERIALS AND METHODS}

\subsection{Sample collection}

As part of an ongoing national surveillance study of acute respiratory tract infections (the ARI-EL study) organised by the National Institute for Public Health and the Environment (RIVM), throat swabs were collected from GP patients with or without complaints of an acute respiratory tract infection from October 2000 to December 2002 [12]. The samples were collected by 67 GPs from 45 practices of the GP network of the Continuous Morbidity Registration of the NIVEL. Their patient population accounts for ca. $1 \%$ of the Dutch population and is representative according to age, gender, regional distribution and degree of urbanisation. Patients with a diagnosed acute respiratory infection (case) were included if: it was their first visit to the doctor in this episode of acute respiratory infection; the complaints started not more than 5 days before this GP visit; and no antimicrobial agents or antivirals were used in the previous 2 weeks. Within 7 days after including a patient with acute respiratory infection, a control patient without acute respiratory infection in the previous 2 weeks was asked to participate. Furthermore, the control patient had to be in the same age category as the case, must not belong to the same household as the case, and must not have used any antimicrobial agents or antivirals in the previous 2 weeks [12].

The specimens collected were forwarded to the Microbiological Laboratory of The University Hospital Maastricht for analysis of the commensal streptococcal throat flora. Upon arrival, specimens were suspended in $3 \mathrm{~mL}$ of sterile saline $(0.9 \% \mathrm{NaCl}, \mathrm{w} / \mathrm{v})$ and $500 \mu \mathrm{L}$ of this suspension was centrifuged at $14000 \mathrm{rpm}$ for $10 \mathrm{~min}$. The pellet was suspended in $1 \mathrm{~mL}$ of $0.7 \%$ peptone $(\mathrm{w} / \mathrm{v}) \mathrm{with}$ $30 \%$ glycerol $(\mathrm{v} / \mathrm{v})$ and stored at $-20^{\circ} \mathrm{C}$ until further analysis.

\subsection{Determination of the erythromycin resistance phenotype}

The total indigenous oropharyngeal flora, i.e. $\alpha$ - haemolytic and non-haemolytic streptococci, was cultured to determine resistance to erythromycin. After thawing, the samples were centrifuged at 14 $000 \mathrm{rpm}$ for $10 \mathrm{~min}$ and the pellet was suspended in $500 \mu \mathrm{L} 0.9 \% \mathrm{NaCl}(\mathrm{w} / \mathrm{v})$. Then, $40 \mu \mathrm{L}$ of 10 -fold dilutions were inoculated using a spiral plater (Eddy Jet; IUL Instruments, I.K.S., Leerdam, The Netherlands) onto Columbia agar (CM331; Oxoid, Basingstoke, UK) plates supplemented with 5\% sheep blood and containing $0 \mathrm{mg} / \mathrm{L}, 1 \mathrm{mg} / \mathrm{L}$ and $16 \mathrm{mg} / \mathrm{L}$ erythromycin. From the samples showing growth following overnight incubation at $37^{\circ} \mathrm{C}$, colonies with the morphology of streptococci were counted. Per swab, only the colonies growing on the agar plate with the highest concentration of erythromycin (i.e. isolates of the $1 \mathrm{mg} / \mathrm{L}$ plates showing growth on this plate only, or isolates of the 16 $\mathrm{mg} / \mathrm{L}$ plates in cases of growth on both antibiotic-containing plates) were subcultured and stored at $70^{\circ} \mathrm{C}$ until further analysis of the resistance genes.

The prevalence of resistance for each concentration of erythromycin was calculated as the ratio between the number of samples showing growth at that specific erythromycin concentration and the total number of samples tested multiplied by $100 \%$. 
Nys, S., Tjhie, J.H.T., Bartelds, A.I.M., Heijnen, M.L.A., Peeters, M.F., Stobberingh, E.E. Erythromycin resistance in the commensal throat flora of patients visiting the general

practitioner: a reservoir for resistance genes for potential pathogenic bacteria.

International Journal of Antimicrobial Agents: 26, 2005, nr. 2, p. 133-137

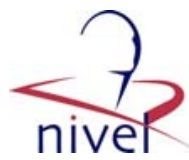

\subsection{Detection of the erythromycin resistance genes}

For the identification of the different erythromycin resistance genes (ermB and mefA), total DNA was extracted from bacteria grown on blood agar plates (Oxoid, Basingstoke, UK). Polymerase chain reaction (PCR) was performed within a Perkin-Elmer Cetus GeneAmp PCR system 9600 (PerkinElmer, Norwalk, CT) yielding PCR products of 425 base pairs (bp) and $348 \mathrm{bp}$, respectively, for ermB and mefA, as described previously $[8,13,14]$. Positive control strains for ermB JH2-2:Tn1545 [14] and mefA O2J1175 [13] were included in each run.

\subsection{Conjugation experiment}

The bacterial strain used as donor of the erythromycin resistance gene ermB was a rifampicinsusceptible isolate from this study. A clinical erythromycin-susceptible $S$. pneumoniae strain made rifampicin $(25 \mathrm{mg} / \mathrm{L})$ resistant was used as recipient. Transfer of the resistance gene was performed in suspension with both donor and recipient grown to the late exponential phase and then mixed at a donor/recipient ratio of 1:5. As a control, each of the donor and recipient strains were mixed with $0.9 \% \mathrm{NaCl}$ in a ratio 1:5. After centrifugation of the mating mixtures, the pellet was suspended in $0.5 \mathrm{~mL} \mathrm{NaCl}(0.9 \%, \mathrm{w} / \mathrm{v})$ and plated on Columbia agar plates (CM331; Oxoid) supplemented with 5\% sheep blood, containing both erythromycin $(16 \mathrm{mg} / \mathrm{L})$ and rifampicin $(25 \mathrm{mg} / \mathrm{L})$. The inoculated plates were incubated at $5 \% \mathrm{CO}_{2}$ and $37^{\circ} \mathrm{C}$. Putative transconjugants were characterised for the presence of the ermB gene by PCR and by pulsed-field gel electrophoresis (PFGE) to detect clonality with the recipient $S$. pneumoniae strain. The frequency of transfer was expressed as the number of transconjugants after mating per recipient colony-forming units in the mating mixture. The stability of the transconjugant was determined by daily successive plating on blood agar without antibiotics.

\subsection{Pulsed-field gel electrophoresis}

In short, agarose plugs containing bacterial chromosomal DNA were digested with SmaI (reference 15228-018; Invitrogen, Breda, The Netherlands) for $6 \mathrm{~h}$ at $37^{\circ} \mathrm{C}$. PFGE was carried out on a CHEFDRII cell (Bio-Rad Laboratories, Richmond, CA), as described previously with minor modifications [15]. The gels were stained with ethidium bromide for $15 \mathrm{~min}$ and photographed under ultraviolet irradiation. The restriction endonuclease digest patterns were visually compared and interpreted using the criteria of Tenover et al. [16].

\section{RESULTS}

\subsection{Sample collection}

Of the 678 patients participating in the study, $60 \%$ were female. The age distribution of the participants was not significantly different from the distribution in the Dutch population, although the 0 - to 4-year-olds were underrepresented and the 14- to 44-year-olds were overrepresented [12].

\subsection{Determination of the erythromycin resistance phenotype}

Indigenous oropharyngeal flora, i.e. $\alpha$-haemolytic and non-haemolytic streptococci, was present in all collected swabs (Table 1). The flora of $292(43 \%)$ patients showed no resistance to either concentration of erythromycin tested. On the $1 \mathrm{mg} / \mathrm{L}$ agar plates $57 \%$ of the samples showed growth, and $20 \%$ were able to grow on the $16 \mathrm{mg} / \mathrm{L}$ agar plates.

\section{[ TABLE 1 ]}

The proportion of erythromycin-resistant streptococci in the total commensal throat flora of each patient ranged from $1 \%$ to $100 \%$, with a median of $1 \%$. Furthermore, $>50 \%$ of the total commensal streptococcal flora were erythromycin resistant $(1 \mathrm{mg} / \mathrm{L})$ in $3 \%$ of the patients.

\subsection{Detection of the erythromycin resistance genes}

The majority of the isolates showing growth only on the $1 \mathrm{mg} / \mathrm{L}$ erythromycin plates carried the mefA resistance gene (78\%) (Table 2). For the isolates on the highest erythromycin concentration plates, the ermBgene was found in the majority of the samples (64\%). Isolates on the higher erythromycin concentration also more often showed the combination of both ermB and mefA genes (9\%) compared with the isolates from the $1 \mathrm{mg} / \mathrm{L}$ agar plates $(2 \%)$.

\section{[ TABLE 2 ]}


Nys, S., Tjhie, J.H.T., Bartelds, A.I.M., Heijnen, M.L.A., Peeters, M.F., Stobberingh, E.E. Erythromycin resistance in the commensal throat flora of patients visiting the general

practitioner: a reservoir for resistance genes for potential pathogenic bacteria.

International Journal of Antimicrobial Agents: 26, 2005, nr. 2, p. 133-137

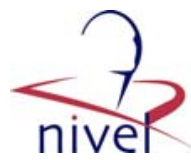

\subsection{Conjugation experiment}

Erythromycin resistance was successfully transferred from the randomly chosen commensal streptococcus isolate (ermB-positive) to a clinical S. pneumoniae strain $\left(\mathrm{ery}^{\mathrm{S}}\right.$, rif $^{\mathrm{R}}$ ) with a frequency of $\pm 1 \times 10^{-9}$. The identification of the transconjugant was confirmed by API strep and was similar to that of the acceptor strain. Furthermore, the ermB gene was detected in the transconjugant by PCR, and PFGE both of the recipient and the transconjugant showed identical restriction patterns. No spontaneous mutations in the control experiments were detected. All the transconjugants were stable, as erythromycin resistance remained after five consecutive platings on antibiotic-free agar plates.

\section{DISCUSSION}

To the best of our knowledge, the present study is one of the few studies dealing with macrolide resistance in the commensal flora of general practice patients in The Netherlands. The prevalence of macrolide resistance in the majority of the patient population and the transferability of macrolide resistance by conjugation to potentially pathogenic micro-organisms with a frequency of $1 \times 10^{-9}$ underscore the relevance of the commensal flora as source of antibiotic resistance genes. Furthermore, this transfer of resistance genes by conjugation is a process equivalent to the in vivo situation, as bacteria of the commensal throat flora are also found in close proximity to one another.

The two other published studies in The Netherlands on commensal flora were primarily directed at the effect of clarithromycin and/or azithromycin on the appearance of resistance in the commensal flora in a double-blind placebo controlled study [5,6]. In the study by Berg et al. [5], 296 patients with documented coronary artery disease were randomised to receive either 2 weeks of slow release (SR) clarithromycin or placebo for 2 weeks. SR clarithromycin had a major effect on the appearance of resistance in the commensal throat flora, which persisted for at least 8 weeks after the end of therapy. Matute et al. [6] did not find any effect of a 3-day course of azithromycin or 7-day course of clarithromycin on the commensal throat flora in each of six healthy volunteers. Explanations for the lack of effect of the tested macrolides in the latter study are the small number of participants and the shorter duration of therapy.

The resistance percentage in our study was lower than the $71 \%$ macrolide-resistant viridans group streptococci (the predominant species of the oropharyngeal commensal flora) found in Belgian healthy volunteers in 2003 [17] and the rate reported in Spain in 2001 [9]. These results are in accordance with the lower antibiotic use in general [18], and especially macrolides [19], in The Netherlands compared with both other countries. Also, in our study the resistance prevalence was determined in the total commensal streptococcal throat flora compared with only a selected subpopulation of this flora in both other studies, which might have resulted in higher resistance percentages compared with our results.

Twenty percent of the patients in our study carried streptococci resistant to a high concentration of erythromycin $(16 \mathrm{mg} / \mathrm{L})$. As the majority of the streptococci growing on the $16 \mathrm{mg} / \mathrm{L}$ agar plates (64\%) carried the ermB gene, it seems that resistance to a high erythromycin concentration in the population studied is correlated with the $\mathrm{MLS}_{\mathrm{B}}$ phenotype that confers cross-resistance to macrolides, lincosamides and streptogramins. The same relationship was also found by P'erez-Trallero et al. [9]. Furthermore, similar to our study, their study showed that all commensal streptococci with the $\mathrm{M}$ phenotype had low minimum inhibitory concentrations (MICs) for macrolides, clindamyc in and streptogramin B. In our isolates, $78 \%$ of the isolates growing only on the $1 \mathrm{mg} / \mathrm{L}$ agar plates contained the mefA gene.

None of the resistance genes studied were detected in $5 \%$ of the isolates growing on the higher concentration of erythromycin and in $10 \%$ of the isolates growing on the lower concentration. The mechanisms of resistance in these isolates are therefore unknown. This finding might imply the existence of other resistance genes or mechanisms. For the lower erythromycin-resistant strains, a likely explanation might be an altered secretion pathway for the antimicrobial agent or modified entry. For the higher erythromycin-resistant strains, the ermA gene subclass ermTR might be responsible for the $\mathrm{MLS}_{\mathrm{B}}$ phenotype, as this gene is known to code for the iMLS $\mathrm{B}_{\mathrm{B}}$ phenotype in $S$. pyogenes isolates [20] and in $\beta$-haemolytic streptococci group B, C and G [4,21].

A limitation of the study was the identification of the isolates by morphology only. However, the aim of the study was to determine the prevalence of erythromycin resistance in the total commensal 
Nys, S., Tjhie, J.H.T., Bartelds, A.I.M., Heijnen, M.L.A., Peeters, M.F., Stobberingh, E.E. Erythromycin resistance in the commensal throat flora of patients visiting the general practitioner: a reservoir for resistance genes for potential pathogenic bacteria. International Journal of Antimicrobial Agents: 26, 2005, nr. 2, p. 133-137

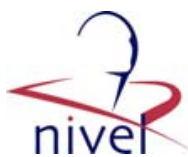

streptococcal flora. Thus, the morphology alone was sufficient to distinguish between streptococci and non-streptococci (mostly staphylococci).

The present results confirmed that the commensal throat flora forms a large reservoir of resistance genes able to transfer their erythromycin resistance genes by horizontal gene transfer to a potential pathogenic S. pneumoniae, which consequently becomes resistant to commonly used antimicrobials. How often this occurs depends on the number of genes involved in resistance, the ability of these genes to be transferred, the prevalence of pathogenic bacteria, the prevalence of resistant commensal throat flora and the relative contribution of resistant flora to the total commensal flora. The latter two factors are influenced by the use of antibiotics. The transfer is relatively easy for macrolide resistance as this is often encoded by one gene only, often located on transposons [22,23]. As shown in a previous study [24], mefE could be transferred with a frequency of $\pm 1 \times 10^{-7}$ from viridans group streptococci to S. pneumoniae by transformation. However, transformation is considered an in vitro phenomenon with pre-competent S. pneumoniae R6 cells and total genomic donor DNA. Whether this situation also occurs in vivo is questionable. The conjugation experiment in this study was assayed with bacterial donor and recipient strains mixed in suspension to mimic the in vivo situation. Close contact between micro-organisms not pre-treated to achieve competent cells is very likely a common situation in vivo.

Macrolide resistance in potentially pathogenic Gram-positive bacteria is still relatively low in The Netherlands, but it is increasing [25]. Judicious use of macrolide antibiotics is essential to keep macrolides as alternatives for penicillins in the future, especially in patients with severe forms of allergy to $\beta$-lactam antibiotics.

\section{ACKNOWLEDGMENTS}

We would like to thank all the patients and general practitioners willing to participate in the study. Furthermore, we would like to thank Kim Spee for his technical assistance.

\section{TABLES}

Table 1

Culture results of the oropharyngeal swabs and erythromycin resistance prevalence $(\%)$ of the streptococcal isolates

\begin{tabular}{lc}
\hline & Total \\
\hline Number of patients & 678 \\
Number of samples with growth on $1 \mathrm{mg} / \mathrm{L}$ plates & 386 \\
Number of samples with growth on $16 \mathrm{mg} / \mathrm{L}$ plates & 138 \\
Prevalence of resistance for $1 \mathrm{mg} / \mathrm{L}(\%)$ & 57 \\
Prevalence of resistance for $16 \mathrm{mg} / \mathrm{L}(\%)$ & 20 \\
\hline
\end{tabular}

Table 2

Polymerase chain reaction (PCR) results of the erythromycin-resistant streptococcal isolates

\begin{tabular}{|c|c|c|c|c|c|}
\hline \multirow[t]{2}{*}{ Concentration of erythromycin (mg/L) } & \multirow[t]{2}{*}{$N^{\mathrm{a}}$} & \multicolumn{4}{|c|}{ Number (\%) of isolates with the resistance gene } \\
\hline & & erm B & mefA & erm $\mathrm{B}+$, mef $\mathrm{A}+$ & erm $\mathrm{B}-$, mefA- \\
\hline 1 & 294 & $29(10)$ & $230(78)$ & $5(2)$ & $30(10)$ \\
\hline 16 & 188 & $121(64)$ & $42(22)$ & $16(9)$ & $9(5)$ \\
\hline
\end{tabular}

\section{REFERENCES}

[1] Makela MJ, Puhakka T, Ruuskanen O, et al. Viruses and bacteria in the etiology of the common cold. J Clin Microbiol 1998;36:539- 42.

[2] Diaz-Mejia JJ, Carbajal-Saucedo A, Amabile-Cuevas CF. Antibiotic resistance in oral commensal streptococci from healthy Mexicans and Cubans: resistance prevalence does not mirror antibiotic usage. FEMS Microbiol Lett 2002;217:173-6.

[3] Andremont A. Commensal flora may play key role in spreading antibiotic resistance. ASM News 2003;69:601-7.

[4] Seppala H, Haanpera M, Al-Juhaish M, Jarvinen H, Jalava J, Huovinen P. Antimicrobial susceptibility patterns and macrolide resistance genes of viridans group streptococci from normal flora. J Antimicrob Chemother 2003;52:636-44. 
Nys, S., Tjhie, J.H.T., Bartelds, A.I.M., Heijnen, M.L.A., Peeters, M.F., Stobberingh, E.E.

Erythromycin resistance in the commensal throat flora of patients visiting the general

practitioner: a reservoir for resistance genes for potential pathogenic bacteria.

International Journal of Antimicrobial Agents: 26, 2005, nr. 2, p. 133-137

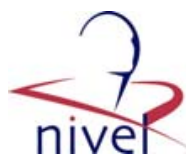

[5] Berg HF, Tjhie JH, Scheffer GJ, et al. Emergence and persistence of macrolide resistance in oropharyngeal flora and elimination of nasal carriage of Staphylococcus aureus after therapy with slow-release clarithromycin: a randomized, double-blind, placebocontrolled study. Antimicrob Agents Chemother 2004;48:4183-8.

[6] Matute AJ, Schurink CA, Krijnen RM, Florijn A, Rozenberg-Arska M, Hoepelmen IM. Double-blind, placebo-controlled study comparing the effect of azithromycin with clarithromycin on oropharyngeal and bowel microflora in volunteers. Eur J Clin Microbiol Infect Dis 2002;21:427-31.

[7] Leclercq R. Mechanisms of resistance to macrolides and lincosamides: nature of the resistance elements and their clinical implications. Clin Infect Dis 2002;34:482-92.

[8] Sutcliffe J, Tait-Kamradt A, Wondrack L. Streptococcus pneumoniae and Streptococcus pyogenes resistant to macrolides but sensitive to clindamycin: a common resistance pattern mediated by an efflux system. Antimicrob Agents Chemother 1996;40:1817-24.

[9] Perez-Trallero E, Vicente D, Montes M, Marimon JM, Pineiro L. High proportion of pharyngeal carriers of commensal streptococci resistant to erythromycin in Spanish adults. J Antimicrob Chemother 2001;48:225-9.

[10] Hoban DJ, Wierzbowski AK, Nichol K, Zhanel GG. Macrolideresistant Streptococcus pneumoniae in Canada during 1998-1999: prevalence of $\operatorname{mef}(\mathrm{A})$ and erm(B) and susceptibilities to ketolides. Antimicrob Agents Chemother 2001;45:2147-50.

[11] Reinert RR, Al-Lahham A, Lemperle M, et al. Emergence of macrolide and penicillin resistance among invasive pneumococcal isolates in Germany. J Antimicrob Chemother 2002;49:61-8.

[12] van den Brandhof WE, Bartelds AIM, Peeters MF, Heijnen MLA. ARI-EL: a case-control study on acute respiratory infections in general practitioner patients. Interim report of October 2000 through September 2001. RIVM rapport 217617006 2002. http://www.rivm.nl/bibliotheek/ [accessed 21 April 2005].

[13] Sutcliffe J, Grebe T, Tait-Kamradt A, Wondrack L. Detection of erythromycin-resistant determinants by PCR. Antimicrob Agents Chemother 1996;40:2562-6.

[14] Jensen LB, Frimodt-Moller N, Aarestrup FM. Presence of erm gene classes in Gram-positive bacteria of animal and human origin in Denmark. FEMS Microbiol Lett 1999;170:151-8.

[15] Chiou CS, Liao TL, Wang TH, Chang HL, Lias JC, Li CC. Epidemiology and molecular characterization of Streptococcus pyogenes recovered from scarlet fever patients in central Taiwan from 1996 to 1999. J Clin Microbiol 2004;42:3998-4006.

[16] Tenover FC, Arbeit RD, Goering RV, et al. Interpreting chromosomal DNA restriction patterns produced by pulsed-field gel electrophoresis: criteria for bacterial strain typing. J Clin Microbiol 1995;33:2233-9.

[17] Malhotra-Kumar S, Lammens C, Martel A, et al. Oropharyngeal carriage of macrolide-resistant viridans group streptococci: a prevalence study among healthy adults in Belgium. J Antimicrob Chemother 2004;53:271-6.

[18] Molstad S, Lundborg CS, Karlsson AK, Cars O. Antibiotic prescription rates vary markedly between 13 European countries. Scand J Infect Dis 2002;34:366-71.

[19] Cars O, Molstad S, Melander A. Variation in antibiotic use in the European Union. Lancet 2001;357:1851-3.

[20] Seppala H, Skurnik M, Soini H, Roberts MC, Huovinen P. A novel erythromycin resistance methylase gene (ermTR) in Streptococcus pyogenes. Antimicrob Agents Chemother 1998;42:25762.

[21] Portillo A, Lantero M, Olarte I. MLS resistance phenotypes and mechanisms in beta-haemolytic group B, C and G Streptococcus isolates in La Rioja, Spain. J Antimicrob Chemother 2001;47: 1156.

[22] McDougal LK, Tenover FC, Lee LN, et al. Detection of Tn917- like sequences within a Tn916-like conjugative transposon (Tn3872) in erythromycin-resistant isolates of Streptococcus pneumoniae. Antimicrob Agents Chemother 1998;42:2312-8.

[23] Roberts AP, Cheah G, Ready D, Pratten J, Wilson M, Mullany P. Transfer of TN916-like elements in microcosm dental plaques. Antimicrob Agents Chemother 2001;45:2943-6.

[24] Cerda Zolezzi P, Laplana LM, Calvo CR, Cepero PG, Erazo MC, Gomez-Lus R. Molecular basis of resistance to macrolides and other antibiotics in commensal viridans group streptococci and Gemella spp. and transfer of resistance genes to Streptococcus pneumoniae. Antimicrob Agents Chemother 2004;48: 3462-7.

[25] SWAB. NethMap 2004-consumption of antimicrobial agents and antimicrobial resistance among medically important bacteria in The Netherlands. http://www.swab.nl/swab/swabfu.nsf/uploads/ 4725079A0D5E0FDCC1256EBA003530EA/\$file/nethmap 2004.pdf [accessed 24 May 2005]. 